\title{
The Impact of SHGs on Women Development: A Study of Kummanpally Village, Andhra Pradesh (India).
}

\author{
MarotiN.Gaikwad ${ }^{1}$, SrihariC.Reddy ${ }^{2}$ \\ ${ }^{1}$ Assistant Professor (BMCs College of Social Work, Chopda, Jalgaon, MS, India.) \\ ${ }^{2}$ Child Protection Officer (District Child Protection Unit, Dept.Of Women and Child, Nizamabad, AP, India)
}

\begin{abstract}
The self help group is functioning very effective dimension role at creating rural livelihood at sustain, the savings and group activities are eliminating poverty and creating the effective social functions by participating women at village level committees as a member at each and every village level committees. The self help group members are very active part of an economical status, through Banks and MandalSamakya (Mandal level function organization to educate and give the loans) they are getting the loan, and loan amount is utilizing for purposeful fields and at their children education, economic activity. In this village $90 \%$ of eligible women are member in any one of self help group and they are all participating at meetings and reimburse the loan amount to the bank in time, by it they are getting governmental scheme benefits and through the self help groups the women educating at all aspects of social functions and also creating the awareness at prevent malpractices and making better social adjustment. And it creates self-reliance, self-esteem, self-production, joint responsibility, self-determination by mobilizing internal indigenous resources of the person the group. Through it women educating the total family members are mobilizing at all concerns.
\end{abstract}

Keyword:Development, Economic status, Participation, Responsibility, Saving,

\section{Introduction}

Self-Help groups have been getting more importance for work with people and community, for common purpose and solving the problems which are related social-economical, and to self-reliance, selfesteem, self-production, joint responsibility, self-determination by mobilizing internal indigenous resources of the person the group. They work together to achieve the goals and accomplishment of the work and to come plat-form.

Self-Help Group is a small voluntary association of poor people preferably from the same socioeconomic back drop. The micro-credit given to them makes them enterprising; it can be all women group, allmen group or even a mixed group. However, it has been the experience that women's groups perform better in all the important activities of SHGs.

Self help group are voluntary, small group structure for mutual aid and the accomplishment of social purpose, they are usually formed by peers who have come together for mutual assistance in satisfying a common handicap or life-disrupting problem and bringing about desired social and or personal change. The initiators of such groups emphasize face to face of personal responsibility by members as well as emotional support, they are frequently "cause" oriented, and promulgate an ideology or values through which members may attain an identity

Such values imply objectives and practices that are broadly beneficial and not harmful, both to the welfare of members participation, and to the wider society, in term of principles of justice, morality and concerns for one's fellow humans.

SHG give assistance to women those are Under BPL, and it fight against oppression of women, it is scheme for rural poverty eradication and prevent the credit from moneylenders, SHGs are being good performance to give the assistance to women, it develops the, we feeling, and self esteem, will power, self confidence to SHG member..

"Self help groups are voluntary, small group structure for mutual aid and the accomplishment of social purpose; they are usually formed by peers who have come together for mutual assistance in satisfying a common handicap or life-disrupting problem and bringing about desired social and or personal change. The initiators of such groups emphasize face to face of personal responsibility by members as well as emotional support, they are frequently "cause" oriented, and promulgate an ideology or values through which members may attain an identity". By Alfred H. KATZ.

\section{Emerergence Of The Shgs Movement}

While no definitive date has been determined for the actual conception and propagation of SHGs, the practice of small groups of rural and urban people banding together to form a savings and credit organization is 
well established in India. In the early stages, NGOs played a pivotal role in innovating the SHG model and in implementing the model to develop the Process fully. In the 1980s, policy makers took notice and worked with development organizations and bankers to discuss the possibility of promoting these savings and credit groups. Their efforts and the simplicity of SHGs helped to spread the movement across the country. State governments established revolving loan funds which were used to fund SHGs. By the 1990s, SHGs were viewed by state governments and NGOs to be more than just a financial intermediation but as a common interest group, working on other concerns as well. The agenda of SHGs included social and political issues as well. The spread of SHGs led also to the formation of SHG Federations which are a more sophisticated form of organization that involve several SHGs forming into Village Organizations (VO) / Cluster Federations and then ultimately into higher level federations (called as MandalSamakhya (MS) in AP or SHG Federation generally). SHG Federations are formal institutions while the SHGs are informal. Many of these SHG federations are registered as societies, mutual benefit trusts and mutually aided cooperative societies. SHG Federations resulted in several key benefits including:

- Stronger political and advocacy capabilities

- Sharing of knowledge and experiences

- Economies of scale

- Access to greater capital

\subsection{Self Helf Group Movement In India}

First time NGOs in India especially after 1970 have started Self-Help groups as a saving and credit activities among the disadvantaged section of the society. Providing the assistance by NABARD has generates focus and sustained support for micro-credit programs. SERP scheme for elimination of rural poverty and DRDA (district rural development agency).Micro-credit has taken the shape of a movement and caught attention of the planners, policy makers, financial institutions, banks, etc NGO sector deserves the credit for initially establishing the efficiency of SHG /Micro-credit approach. Through policy intervention in 1992, NABARD has generates greater focus and sustained for micro-credit program's.

\subsection{SHGs - A Movement In Andhra Pradesh}

Actually, we known the self help group as DWACRA called in Andhra Pradesh but now it changes as slowly as "MahilaSangam"(self help group) whatever may be most of respondents the introduced their self as DWACRA group member. The Government of Andhra Pradesh has taken up the theme of women's Empowerment as one of the strategies to tackle the socio - economic poverty. Self Help movement through savings has been taken up as a mass movement by women- a path chosen by them to shape their destiny for better. Development Agenda of the State in the last few years placing the people, especially women in the fore front has enabled

Formation of a large number of Self Help Groups (SHGs) throughout the State and majority of women are saving one rupee a day. The State government is consciously making an effort to assist SHGs by providing Revolving Fund / Matching grant under various programs.

There are about 4.65 lakhs women SHGs in Andhra Pradesh covering nearly 61.70 lakhs poor women. Andhra Pradesh alone has about half of SHGs organized in the Country. The SHGs are also popularly called DWCRA Groups, ant this name became popular after the DWCRA programs (Development of Women and Children in Rural Areas) through which women's groups were assisted initially. The SHGs are not only resorting to thrift but also are taking small loans out of the corpus available with the group. The group corpus consists of savings, government assistance and also bank loan. Members use the loan out of group corpus for their personal needs initially. However in the long run such loans are utilized for income generation activities. Since inception an amount of Rs. 1556.90 corers is mobilized as corpus by these groups.

\section{Purpose Of Study}

1 The study of Socio-economical status before and after joining in SHG.

2 To study the living standard of women.

3 The study of loan and utilization by SHG member

4 To know the changes of economical status.

\section{1method Of Data Collection}

Data has collected both from Primary and secondary sources. Primary data has collected by using structured interview schedules And secondary data has collected by using Books, Govt.document,journals,newpaper,internet,etc 


\subsection{Sampling Coverage}

We are selected a specific village of "Kummanpally" This village has twenty seven SHG groups and we has took the eighty (80) membersselected by purposeful sampling method.

\subsection{Study Area}

The researcher has been carried out at "kummanpally" Taluka of Bodhan District Nizamabad, AP.

\section{Data Interpretation}

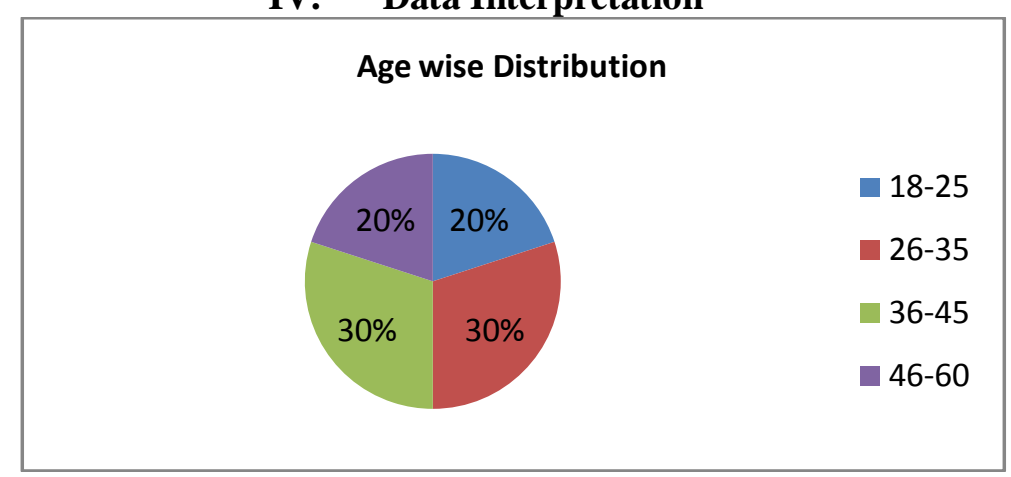

Fig.4.1

Fig.4.1 shows that age is performing vital role in SHG .Nearly 60\% respondents are within 26-45. They are found strengthen in participation and making of decision and desirably achieve the specific goals and overcoming the problems and accomplishment the works which are essential to them with their experience.

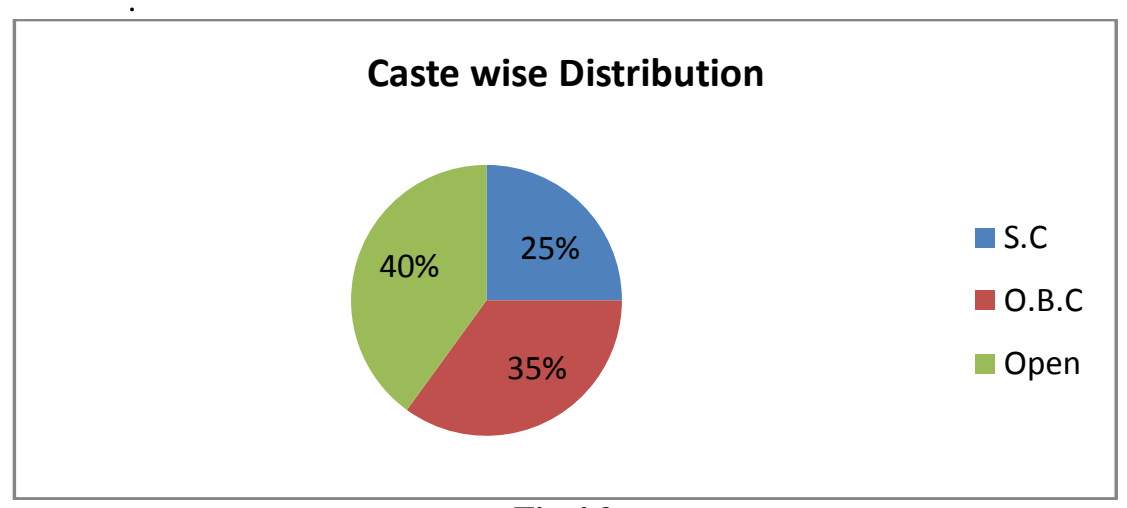

Fig.4.2

Fig.4.2 shows that the women from only three caste groups because of their living the only three caste community, groups i.e. S.C, Open, O.B.C Came together of SHG formation, there are $40 \%$ women from open category, $35 \%$ women from O.B.C category, and rest of $25 \%$ women from open category women are active participating to come platform.

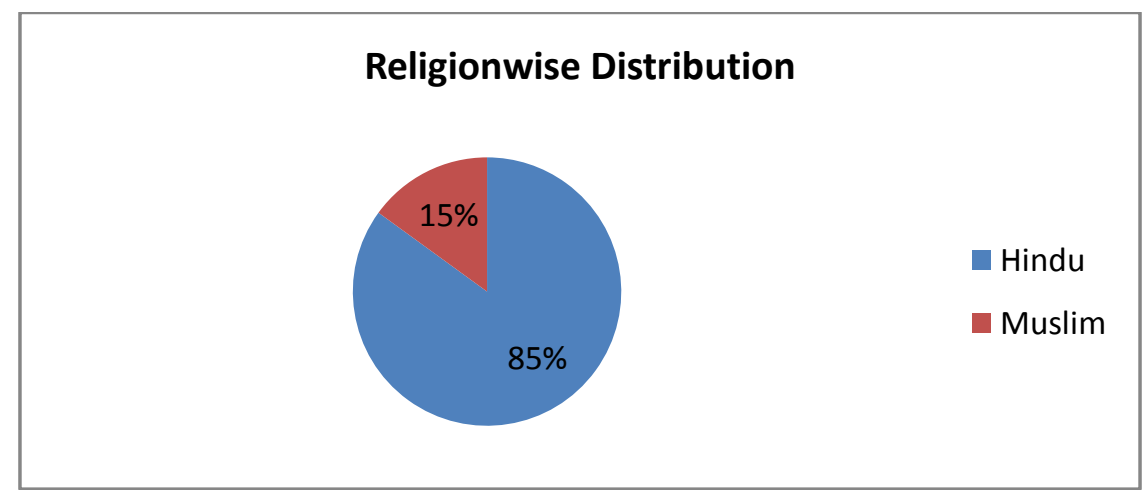

Fig.4.3 
Fig.4.3 shows that, major respondents belongs to Hindu religion percentage is $85 \%$. Another religion is Muslim in this village, women participation percentage is $15 \%$. Actually, fact that the out of population Muslim percentage is low in this village.

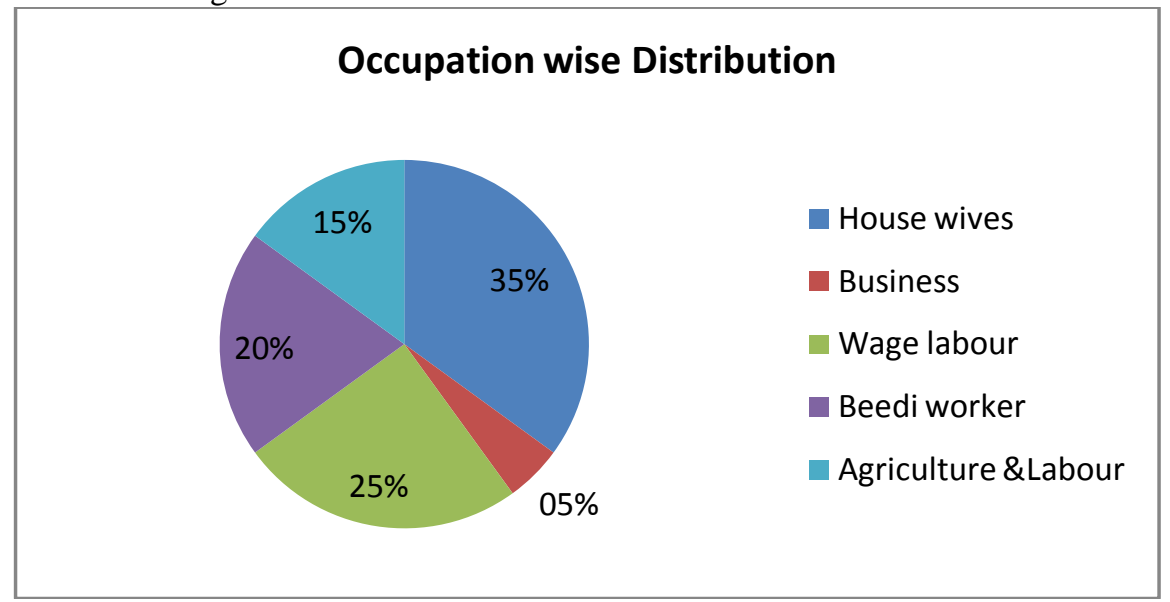

Fig.4.4

Fig.4.4 shows that occupational status of women members' $35 \%$ majority of house wives in participating in the self help group and another are engaged in wage labour in the specific sector of agriculture and bonded to Beedi worker proportion is $20 \%$. And most of respondents doing after agriculture

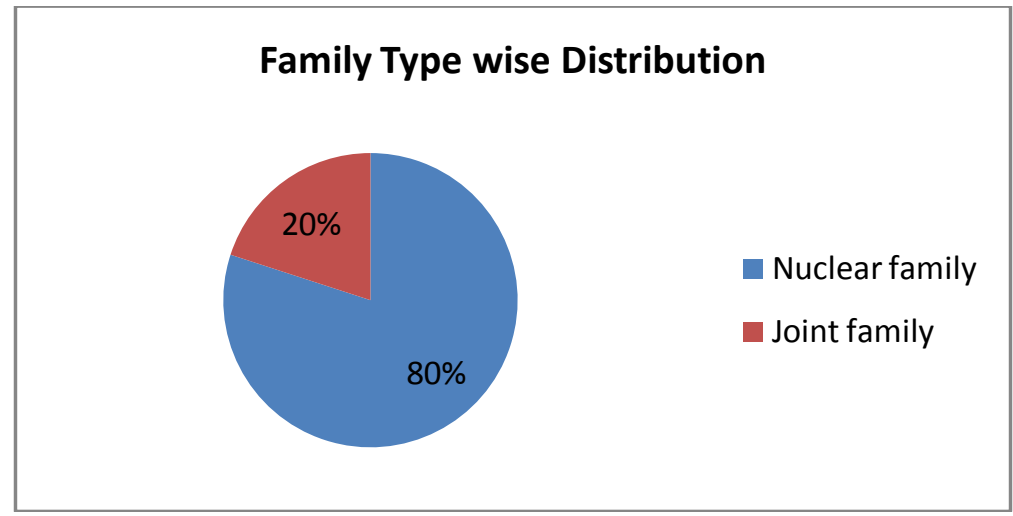

Fig.4.5

Following fig. 4.5 indicates that majority of respondents i.e. $80 \%$ belongs to nuclear family and $20 \%$ respondents are from joint family. It shows that women from nuclear family have more freedom for participation in Self-help Groups.

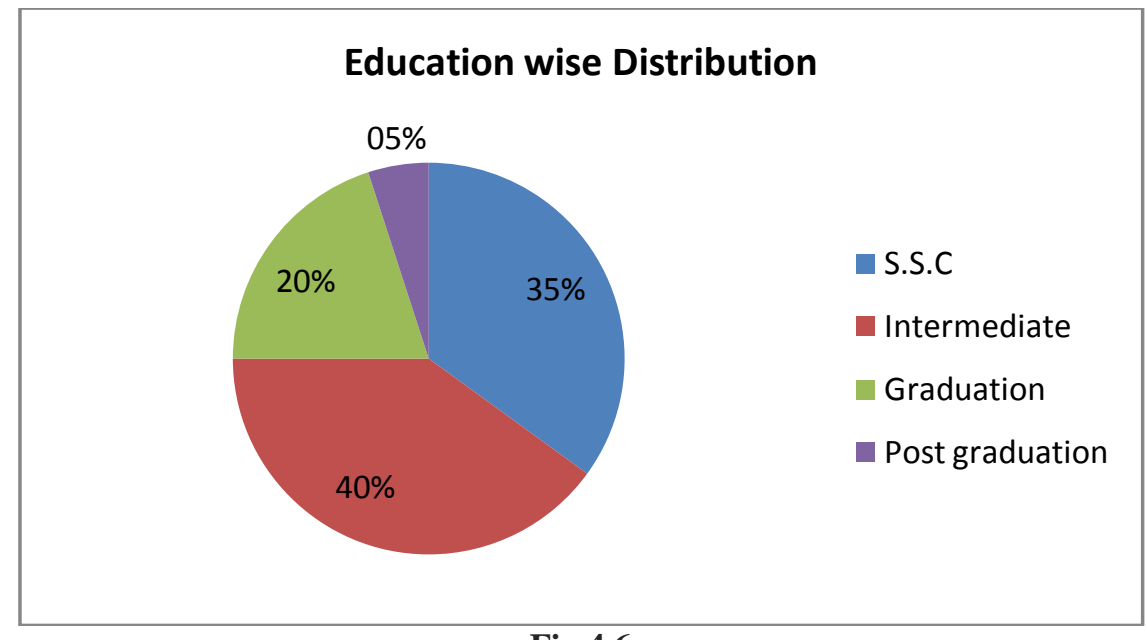

Fig.4.6 
A fig.4.6 show that educations of their children are high $40 \%$ is intermediate, and post graduation is very low $5 \%$, S.S.C percentage is $35 \%$. This is one of the determinations of women empowerment by the way of higher education to their children.

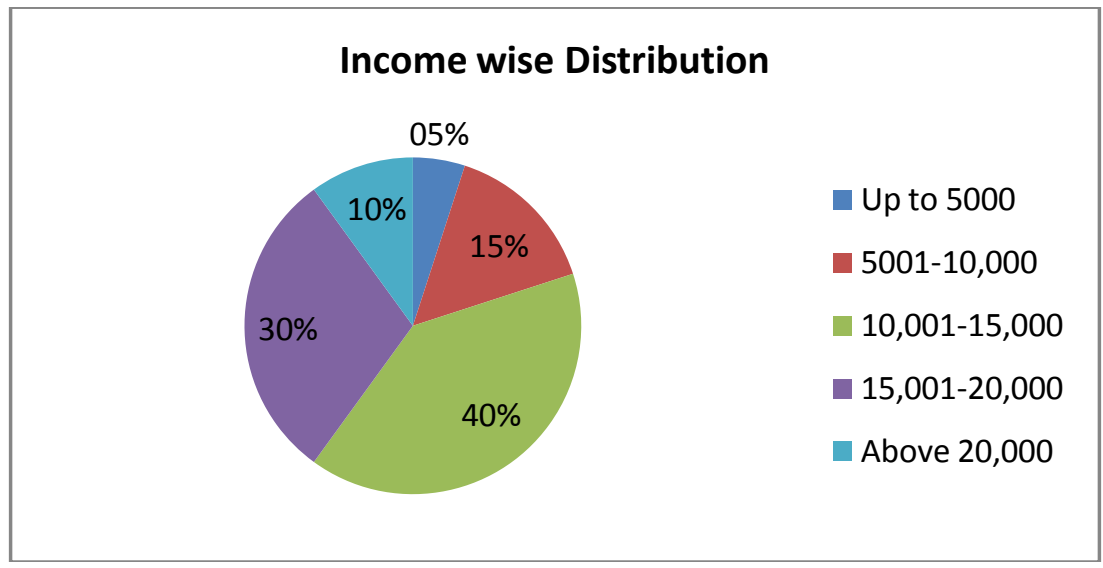

Fig.4.7

Fig.4.7shows that 10000 to 15000 income family respondents are high $40 \%$. By the way of employment program of Indian government strictly implemented in this region income generation is high proportion and well of regular monsoon agriculture production is well. And up to 5000 percentage is very low it is determination the improvement of economical status of women, $10 \%$ is good above 20,000 annual incomes.

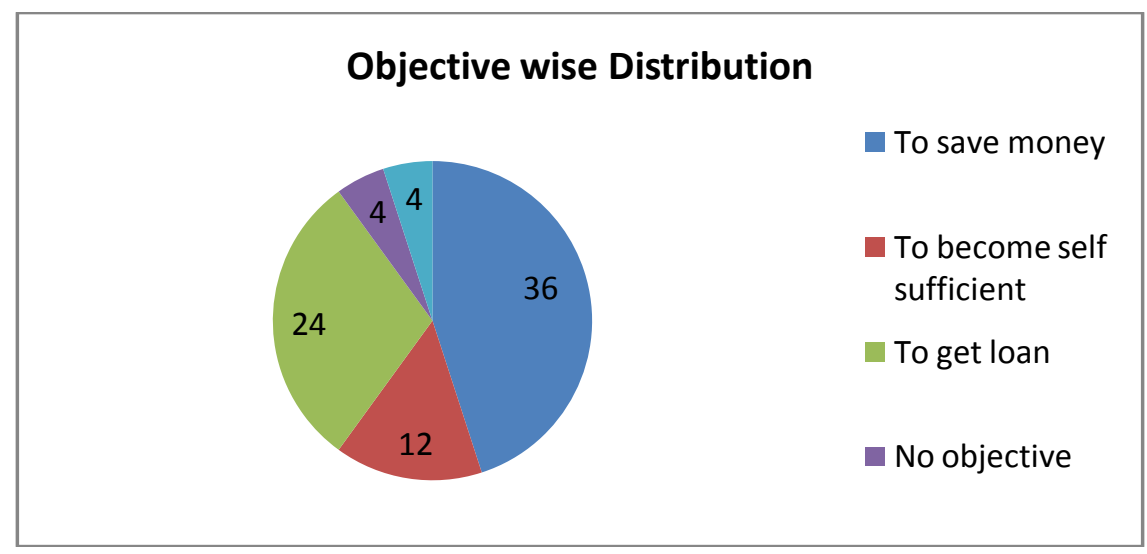

Fig.4.8

Fig.4.8 shows that most of the members join in SHG with specific purpose if not some thy chose after joining and knowing the by importance of self help group to achieve something which is common for to all and accomplishment the task. M Majority of 45\% save money, 30participants were found to be very clear while joining SHG that their need of loan can be easily fulfilled through SHG, rest of 5\% they have not any objective after and before joining in the SHG.

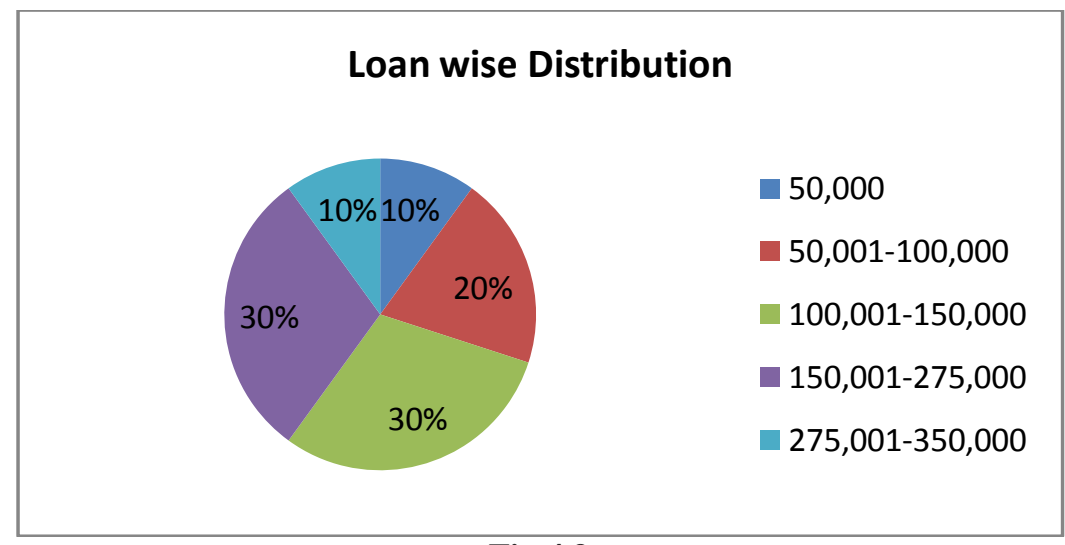

Fig.4.9

Fig.4.9 shows that most of groups get the loan from Gameena Bank and assistance a SHG member can take the loan from the village organization with the reference of group. Grameena Bank provides the loan up to 5 lacks 
to SHG group. After thy disburse the loan monthly wise pay with interest of one rupee but every six months comeback the 75 paisa interest to SHG by forward the record through Bank and MS (mandalsamakya) to state government concern project. $30 \%$ groups have got the loan above 1 lack, $30 \%$ groups have got the loan above 1.5 lakh and two groups got the loan above 3.5 lakh.

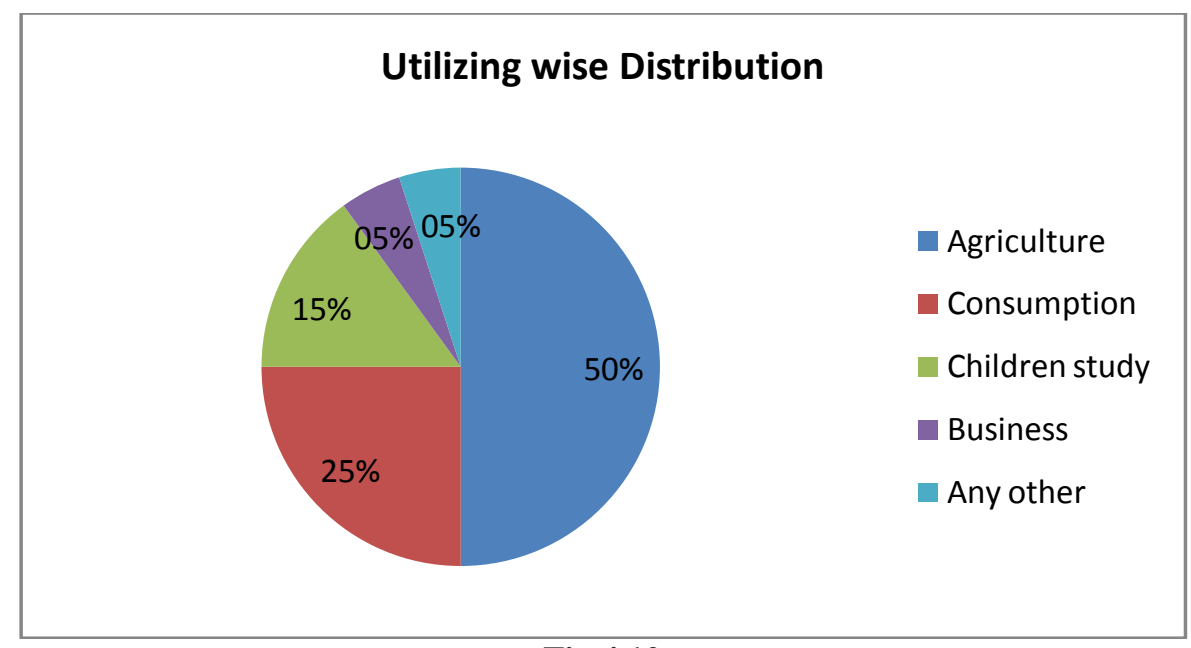

Fig.4.10

Fig.4.10 shown as regard to savings, loan availability and utilization though the amounts are insignificant to not a specific purpose it is going to while suitable purpose. In rural area most of people are getting the credit from money lenders with high interest. But after this SHG loans 50\% women are using for agriculture and stopped the private money lenders, $25 \%$ the purpose of consumption, $5 \%$ business and any other proportion is very low.

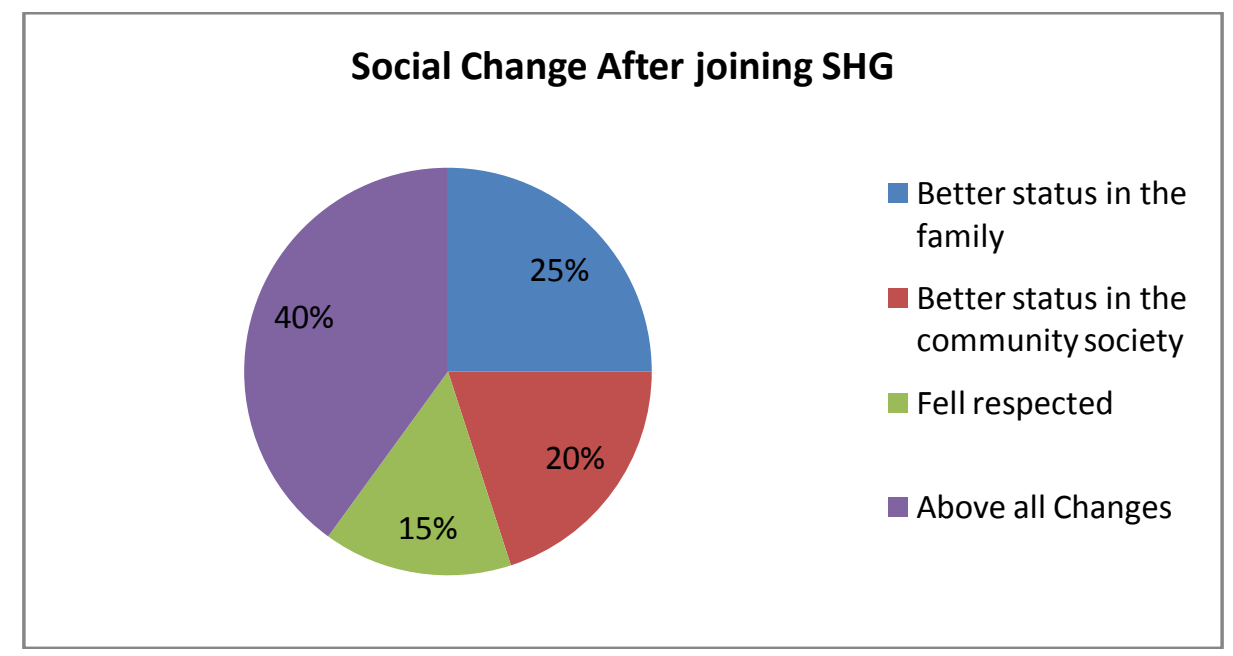

Fig.4.11

Fig. 4.11 shows that, $25 \%$ respondents are enjoying better status in the family, $20 \%$ respondents fell that now they have better status in the society, $15 \%$ fell respected after joining the SHG, and remaining $40 \%$ respondents reported that changes of all facing in their life and nature could occur after joining in theSHG.

\section{Conclusion}

Through this self help groups women are standard their life at aspects, after joining in the Self Help Group with there is a drastically development is occurred in their life with their active participation they are educating at all aspects. And this were strengthen their socio-economic situation, with their active association they are come to know about the study its importance to their children by it they are promoting to their children to make higher study and they are enable to use the local resources affectively and taking the help of organizational agencies services affectively using avail services to their battement of life, it is way to change women and making industrious to her family by best supporting and it is creating the socialization feeling. And they are using the loan amount at very precious purpose like their children education and farming the land, to their survival economic situation and repaying the debits that which was taken at high interest. And with self help group women it is a undependable situation to awake at all aspects. 


\section{References}

[1] YelneGhanshyam, Women's Participation in Self help Group, Perspective in social work, College of Social Work, NirmalNeketan, Mumbai, vol.17, No.1, Jan-April 2002.

[2] women self help groups' success `remarkable', The Hindu, Friday, Aug 19, 2005, Hyderabad, Aug 18 Andhra Pradesh .

[3] CS Reddy, SandeepManak, APMAS CEO-Self-Help Groups: A Keystone of Microfinance in IndiaWomen empowerment \& social security October 2005.

[4] ANUPPALLE, R. REDDY-SELF-HELP GROUPS IN INDIA - A Catalyst for Women Economic Empowerment And Poverty Eradication. 54 Workshop on microfinance.

[5] Reserve Bank of India, Report of the Internal Group to Examine Issues Relating to Rural Credit and Microfinance, July 2005.

[6] Dr. Joy Deshmukh-Ranadive- Women's Self-Help Groups in Andhra Pradesh. Participatory Poverty Alleviation in Action IFAD, IFAD microfinance Project - India, September 2003.

[7] Kropp, Dr. Erhard W. \&Suran, Dr. B.S., Linking Banks and (Financial) Self Help Groups India - An Assessment, November 2002.

[8] NABARD, SHG Bank Linkage Model-wise Cumulative Position up to 31 March 2005

[9] Katz, Alfred H., Application of Self-Help Concept in Current Social Welfare, Social Work, 10 (3) 1965.

[10] Sahoo, U.C., NGOs and Tribal Women's Participation in Self-Help Groups: An Analysis, Tribal Women Welfare, Discovery Publication New Delhi. (1986).

[11] Yelne, G.S. and Shoos, U.C., Women's Empowerment through Self-Help Group,” In Tripathi, S.N. (Ed): Tribal Women in India(1 12), Mohit publication, New Delhi. (2002).

[12] The impact of shelf help group on women development, http://www.andharapradesh.com /a website/programs/selfhelfgrp_imshg.htm.

[13] Yelne G.S., Women's Empowerment Through Self-Help Groups, doctoral diss., S.R.T.M.U.NANDED, sociology, 2005. 